Check for updates

Cite this: RSC Adv., 2018, 8, 42189

Received 15th October 2018 Accepted 9th December 2018

DOI: $10.1039 / \mathrm{c} 8 \mathrm{ra0} 8531 \mathrm{e}$

rsc.li/rsc-advances

\title{
Renewable vanillin based flame retardant for poly(lactic acid): a way to enhance flame retardancy and toughness simultaneously $\dagger$
}

\author{
Pengcheng Zhao, (D) ab Zhiqi Liu, ${ }^{d}$ Xueyi Wang, ${ }^{a}$ Ye-Tang Pan, (D) ${ }^{c}$ Ines Kuehnert, ${ }^{a}$ \\ Michael Gehde, ${ }^{b}$ De-Yi Wang (D) *ac and Andreas Leuteritz*a
}

\begin{abstract}
In this study, a novel bio-based flame retardant material consisting of modified vanillin and poly(lactic acid) (PLA) was developed by incorporation of newly discovered additive, bis(5-formyl-2-methoxyphenyl) phenylphosphonate (VP), into the PLA matrix. The chemical structure of VP was confirmed by ${ }^{1} \mathrm{H}-,{ }^{13} \mathrm{C}-$ and ${ }^{31} \mathrm{P}$ NMR and FTIR. The flame retardancy, thermal behavior as well as the mechanical properties of PLA/VP composites were evaluated. With 5 wt\% of VP, the LOI of PLA increased from 21.4 to 25.8 and passed the UL-94 V-0 classification. Additionally, the elongation at break was improved from 3\% to $11 \%$ without sacrificing tensile strength. In an effort to understand the mechanisms, TGA-FTIR, TGA and SEM were performed. This paper suggests a new possibility to prepare polymeric composites with enhanced flame retardancy from sustainable resources.
\end{abstract}

\section{Introduction}

In recent years, the shortage of fossil resources and environmental pollution caused by plastics has attracted more and more attention. Much effort has been made to find replacements for petroleum-based polymer materials. ${ }^{1}$ Among those polymers, poly(lactic acid) (PLA) is a promising candidate due to its excellent mechanical and optical properties as well as its being a renewable resource. Lactic acid, which is the raw material of PLA, can be produced from biomass like corn, sugarcane, sugar beet and cassava. ${ }^{2}$ PLA is widely used in medical components, packaging materials, automotive and electrical components as well as in households. ${ }^{3-9}$ However, like most of polyesters, PLA is highly inflammable. The low flame resistance has limited its broadened application fields and causes also a potential fire risk. ${ }^{10}$

By now, tremendous investigations have been done aiming to enhance the flame resistance of PLA. Among them,

\footnotetext{
${ }^{a}$ Verarbeitungsprozesse, Leibniz Institut für Polymerforschung Dresden e. V., Hohe Straße 6, 01069, Dresden, Germany.E-mail: leuteritz@ipfdd.de; Tel: +493514658378 ${ }^{b}$ Fakultät für Maschinenbau, Technische Universität Chemnitz, Reichenhainer Straße 70, 09126, Chemnitz, Germany

'IMDEA Materials Institute, C/Eric Kandel, 2, 28906 Getafe, Madrid, Spain. E-mail: deyi.wang@imdea.org; Tel: +34-917871888

${ }^{d}$ Key Laboratory of Comprehensive and Highly Efficient Utilization of Salt Lake Resources, Qinghai Institute of Salt Lakes, Chinese Academy of Sciences, Xining, 810008, China

$\dagger$ Electronic supplementary information (ESI) available: ${ }^{13} \mathrm{C}$ - and ${ }^{31} \mathrm{P}$ NMR spectra of VP (S1), data for TGA of vanillin (VA) and modified vanillin (VP) (S2), SEM and digital pictures of PLA/VA and PLA/VP composites (S3 and S4). See DOI: 10.1039/c8ra08531e
}

nanoparticles and phosphorus containing compounds have attracted more and more attention. Polymer composites based on montmorillonite (MMT) ${ }^{\mathbf{1 1 - 1 3}}$ layered double hydroxide $(\mathrm{LDH}),{ }^{14-17}$ graphene, ${ }^{18,19}$ molybdenum disulfide $\left(\mathrm{MoS}_{2}\right)^{20}$ and carbon nanotubes (CNTs) ${ }^{21,22}$ etc. showed promising flame retardant performance. In the meantime, many polymer nanocomposites possess notable improvement in some mechanical properties. However, the high brittleness of PLA is still an unavoidable drawback. ${ }^{23,24}$ The inherent rigidity of PLA need to be modified to fulfill the demand of spread application..$^{25-27}$

Phosphorus containing flame retardants are well recognized for their advantages of low toxicity, low corrosion and good fire resistance performance. Great variety of phosphorus containing flame retardants has been developed and commercialized, such as ammonium polyphosphate (APP), resorcinol bis (diphenyl phosphate) (RDP), metal phosphinates and 9,10-dihydro-9-oxa10-phosphaphenanthrene-10-oxide (DOPO), etc. However, most of the flame retardants are products of the petrochemical industry. With the growing concerns over environmental issues and depletion of fossil resource, many efforts have been done to prepare bio-based flame retardants from sustainable feedstocks, such as starch, ${ }^{28,29}$ cellulose,${ }^{30}$ chitosan, ${ }^{13}$ cyclodextrin, ${ }^{31}$ lignin, ${ }^{32-34}$ cardanol $^{35}$ and phytic acid, ${ }^{34,36}$ etc.

Vanillin (4-hydroxy-3-methoxybenzaldehyde) is the major component of the extract of vanilla beans and widely used as flavoring in foods, beverages, cosmetics and pharmaceuticals. It has been found that vanillin possesses the antioxidant property and thus can be used as additives or building blocks for functional polymer composites. ${ }^{37,38}$ Besides the direct harvesting from vanilla plants, vanillin can also be produced from lignin, which is the primary component of woody plants. ${ }^{39}$ The first 
industrial production of vanillin is chemical depolymerization of lignin compounds in the waste sulfite liquor which is a byproduct of paper pulping. Nowadays, most of vanillin is produced directly from wood. The high sustainability and the fact that vanillin as the only bio-based aromatics produced from lignin at industrial scale, make vanillin a promising renewable feedstock. ${ }^{40}$

In this work, a novel flame retardant, bis(5-formyl-2methoxyphenyl) phenylphosphonate (VP), was synthesized based on vanillin and characterized by ${ }^{1} \mathrm{H}-,{ }^{13} \mathrm{C}$ - and ${ }^{31} \mathrm{P}$ NMR as well as FTIR. PLA composites were prepared by means of melt compounding. The effect of VP on the thermal properties of PLA was investigated by TGA and DSC. Flame retardancy of PLA composites was determined via LOI, UL-94 and cone calorimeter test. In addition, the flame retardant mechanism was studied using TG-FTIR. The impact of VP on the mechanical properties of PLA was also investigated.

\section{Materials and experimental}

\section{Materials}

Poly(lactic acid), Ingeo Biopolymer 6202D was purchased from NatureWorks LLC. Vanillin (VA) was purchased from TCI Deutschland GmbH. Phenylphosphonic dichloride (PPDC, $90 \%$ ), tetrahydrofuran, triethylamine (TEA) and sodium sulfate anhydrous were purchased from Sigma-Aldrich Corporation. All the materials were used without further purification.

\section{Synthesis of bis(5-formyl-2-methoxyphenyl) phenylphosphonate (VP)}

The synthesis path of VP was shown in Fig. 1. In detail, $0.2 \mathrm{~mol}$ VA and $0.2 \mathrm{~mol}$ TEA were dissolved in $200 \mathrm{ml}$ tetrahydrofuran in a three-neck flask with magnetic stirring. Then, phenylphosphonic dichloride (PPDC, $0.1 \mathrm{~mol}$ ), which dissolved in $100 \mathrm{ml}$ of tetrahydrofuran, was added into the flask dropwise in $2 \mathrm{~h}$. The temperature was kept at $0-5{ }^{\circ} \mathrm{C}$ with ice bath during the addition, and then after removing the ice bath the mixture was stirred for another $5 \mathrm{~h}$ at room temperature, orange solution and white precipitates were produced. The white precipitates, trimethylamine hydrochloride salts, were filtered off. Then the solution was washed with water for 4-5 times and subsequently dried with sodium sulfate anhydrous. After removing the tetrahydrofuran by rotary evaporation, the resulting mixture was dried in a vacuum oven for $24 \mathrm{~h}$ at room temperature. Finally, yellow powder with a melting point of $95{ }^{\circ} \mathrm{C}$ (determined by DSC) was successfully fabricated.

\section{Preparation of PLA/VP composites}

All the PLA composites were prepared by means of melt compounding with a Brabender plasticorder at $160{ }^{\circ} \mathrm{C}$ with a rotation speed of $60 \mathrm{rpm}$ for $6 \mathrm{~min}$. Prior to processing, all the materials were dried in a vacuum oven at $40{ }^{\circ} \mathrm{C}$ overnight. The mixtures were afterward pelletized and injection molded into specimens for further measurements. PLA composites containing $1 \mathrm{wt} \%, 2 \mathrm{wt} \%, 5 \mathrm{wt} \%$ and $10 \mathrm{wt} \%$ of $\mathrm{VP}$ are denoted as PLA1VP, PLA2VP, PLA5VP and PLA10VP. For comparison, pure PLA and PLA composites containing $10 \mathrm{wt} \%$ of vanillin, denoted as PLA10VA, were prepared under the same processing condition owing to have the same processing and heat history.

\section{Characterization techniques}

Nuclear Magnetic Resonance (NMR) measurements were performed with a Bruker Avance III 500 spectrometer (Rheinstetten, Germany) operating at $500 \mathrm{MHz}$. D-Chloroform was used as the solvent and the solvent signal was used for internal calibration $\left(\mathrm{CDCl}_{3}\left({ }^{1} \mathrm{H}\right)=6.27 \mathrm{ppm}\right)$.

The Fourier transform infrared spectroscopy spectra (FTIR) of samples were obtained using the BRUKER VERTEX $80 \mathrm{~V}$ spectrometer over the wavenumber range of $4000-600 \mathrm{~cm}^{-1}$ with a resolution of $4 \mathrm{~cm}^{-1}$.

Scanning electron microscopy (SEM) with energy dispersive X-ray analysis (EDX) was observed via a microscope (Carl Zeiss SMT, Germany) to study the morphological features of PLA composites.

Thermogravimetry-Fourier transform infrared spectroscopy (TG-FTIR) was carried out using a thermogravimetric analyzer, TGA Q5000 (TA Instruments, USA) coupled with Fourier transform infrared spectrometer, Nicolet iS50 (Thermo Electron, USA) in the range between room temperature and $800{ }^{\circ} \mathrm{C}$ at a heating rate of $10 \mathrm{~K} \mathrm{~min}^{-1}$ under nitrogen atmosphere. The FTIR spectra of evolved gaseous products were recorded in the range of $4000-600 \mathrm{~cm}^{-1}$ with a resolution of $4 \mathrm{~cm}^{-1}$ and averaging 8 scans.

Melt flow index (MFI) of composites was determined utilizing a Göttfert MI-4 according to DIN-ISO-1133-2005 at $170{ }^{\circ} \mathrm{C}$ with a weight of $2.16 \mathrm{~kg}$.

Limiting oxygen index (LOI) measurements were carried out with an oxygen index meter (FTT, UK) with the sample dimension of $130 \times 6.5 \times 3 \mathrm{~mm}^{3}$ according to ASTM D2863-97.

A UL-94 vertical burning chamber was employed to fulfill the UL-94 measurements with sample dimension of $130 \times 13 \times 3.2$<smiles>COc1ccc(C=O)cc1O</smiles>

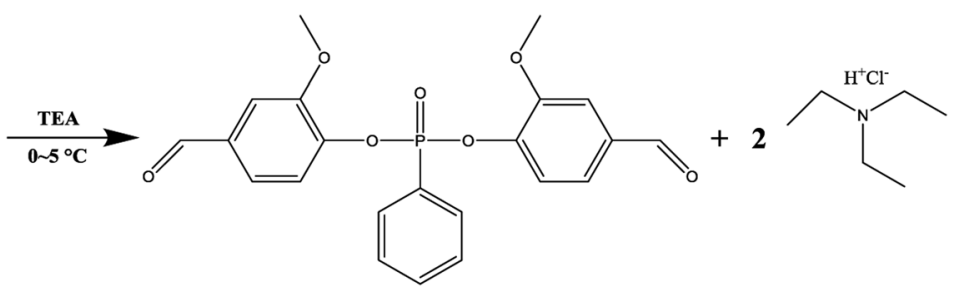

Fig. 1 Synthesis path of VP. 
$\mathrm{mm}^{3}$ according to ASTM D3901. Five samples were tested for each composite.

Cone calorimeter tests were performed via cone calorimeter (FTT, UK) according to the ISO 5660-1 standard with sheet dimension of $100 \times 100 \times 3 \mathrm{~mm}^{3}$ at an external heat flux of 35 $\mathrm{kW} \mathrm{m}{ }^{-2}$, at least two samples were tested for each composite.

Rheological behavior of the composites was evaluated utilizing an ARES rheometer (Rheometrics Scientific, USA) with the sample dimension diameter $=20 \mathrm{~mm}$ and thickness $=2$ $\mathrm{mm}$. Dynamic frequency sweep tests were carried out at $170{ }^{\circ} \mathrm{C}$ with $10 \%$ strain in the frequency range of $0.1-100 \mathrm{rad} \mathrm{s}^{-1}$.

Tensile tests have been done with a Zwick 1456 (model 1456, Z010, Ulm Germany) with crosshead speed $1 \mathrm{~mm} \mathrm{~min}^{-1}$ according to DIN EN ISO 527-2/1BA/1, and for each composition, at least 5 specimens were tested to establish reproducibility. Impact tests were performed on a pendulum impact tester (PSW 4J, Zwick, Germany) to determine the Charpy impact strength according to ISO $179 / 1 \mathrm{eU}$ with the specimen dimension of $80 \times 10 \times 4 \mathrm{~mm}^{3}$, and for each composition at least 10 specimens were tested. Prior to tests, all the specimens were stored in a desiccator for at least 48 hours and then carried out at $23{ }^{\circ} \mathrm{C}$ and $50 \%$ humidity.

\section{Results and discussion}

\section{Structural characterization of VP}

The FTIR spectra of VA and VP are presented in Fig. 2. The strong broad band centered at $3138 \mathrm{~cm}^{-1}$, which was assigned to $\mathrm{OH}$ stretching vibrations, ${ }^{\mathbf{4 1}}$ disappeared in VP. Additionally, a few new characteristic bands have been obtained: the very strong band appeared at $1267 \mathrm{~cm}^{-1}$ could be assigned to the $\mathrm{P}=\mathrm{O}$ stretching vibrations; ${ }^{42}$ the bands appeared at 1214 and $1146 \mathrm{~cm}^{-1}$ corresponded to $\mathrm{P}-\mathrm{O}$ vibrations; ${ }^{43}$ the band observed at $905 \mathrm{~cm}^{-1}$ could be attributed to $\mathrm{P}-\mathrm{C}$ stretching vibrations related to the benzene ring. The FTIR spectra confirmed the desired structure as described in the experimental part.

In order to further validate the successful synthesis of VP, ${ }^{1} \mathrm{H}$-, ${ }^{13} \mathrm{C}$ - and ${ }^{31} \mathrm{P}$ - NMR were carried out. The ${ }^{1} \mathrm{H}$-NMR spectrum is shown in Fig. 3. The structure of VP was confirmed by appearance of chemical shifts at 7.53, 7.63 and 8.05 ppm corresponding to label 5, 4 and 3 attributed to protons of the benzene ring from phenylphosphonic dichloride (PPDC); the chemical shifts at 7.40, 7.44 and 7.45 ppm, labeled 8, 7 and 6, are assigned to the protons of the benzene ring of vanillin structure. The chemical shifts at 3.80 and $9.91 \mathrm{ppm}$ correspond to the protons from the methoxy and aldehyde groups. ${ }^{13} \mathrm{C}$ - and ${ }^{31} \mathrm{P}$ - NMR spectra were summarized as ESI $\dagger$ and shown in $\mathrm{S} 2 . \dagger$

\section{Thermal decomposition behavior}

Thermogravimetric analysis (TGA) was employed to evaluate the thermal decomposition behavior of VA and VP, as well as their effect on the thermal stability of PLA and its composites. The thermal decomposition of VA, VP and PLA as well as PLA composites under a nitrogen atmosphere, was evaluated via TGA with the heating rate of $10 \mathrm{~K} \mathrm{~min}^{-1}$. The resulting curves are shown in Fig. 4. $T_{5 \%}$ is usually considered as the initial decomposition temperature. The relative thermal stability of composites was evaluated by comparing $T_{20 \%}, T_{\max }$ and the residual mass at $500{ }^{\circ} \mathrm{C}$. These detail data of VA and VP are summarized in $\mathrm{S} 1 . \dagger$

Like many other food additives, vanillin is relatively more sensitive to heat than normal additives for thermoplastics. The TGA results showed that pure vanillin started to lose weight at around $80{ }^{\circ} \mathrm{C}$, and subsequently showed a $T_{\max }$ of $175{ }^{\circ} \mathrm{C}$, indicating that vanillin has a volatile nature. And this poor

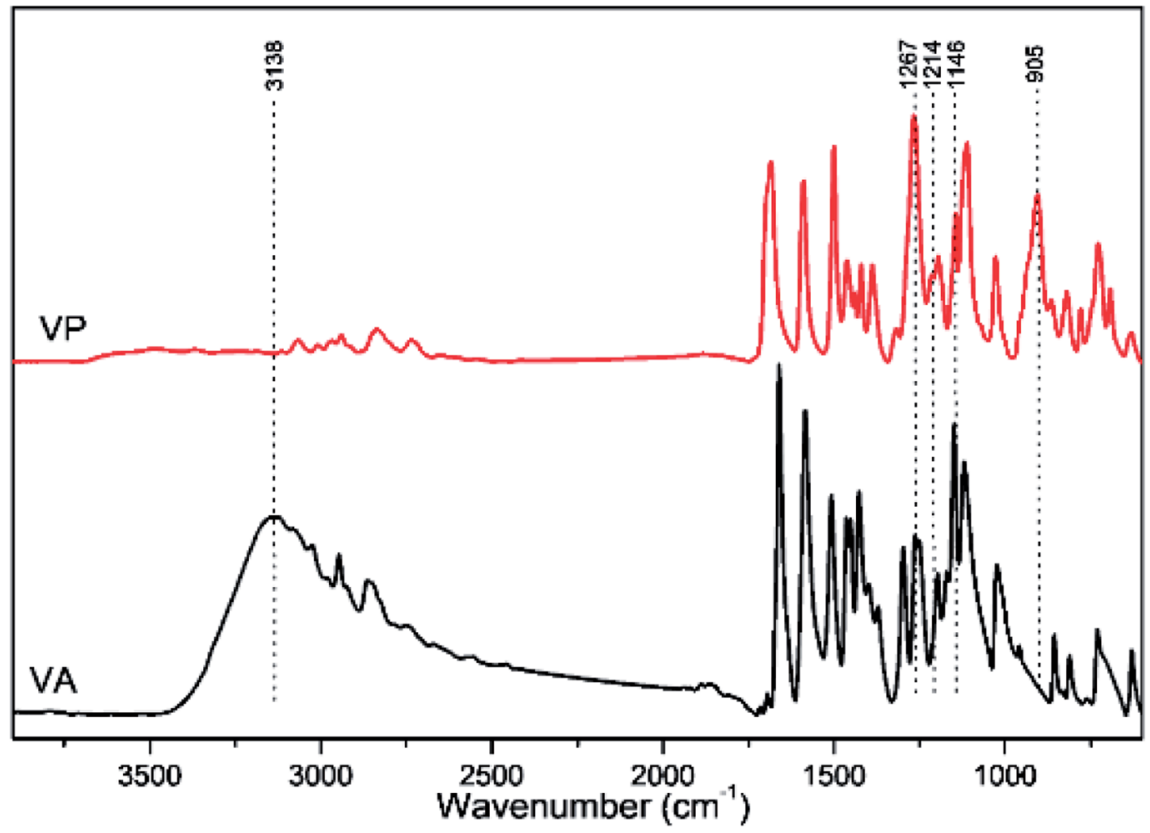

Fig. 2 FTIR Spectra of VA (black) and VP (red). 


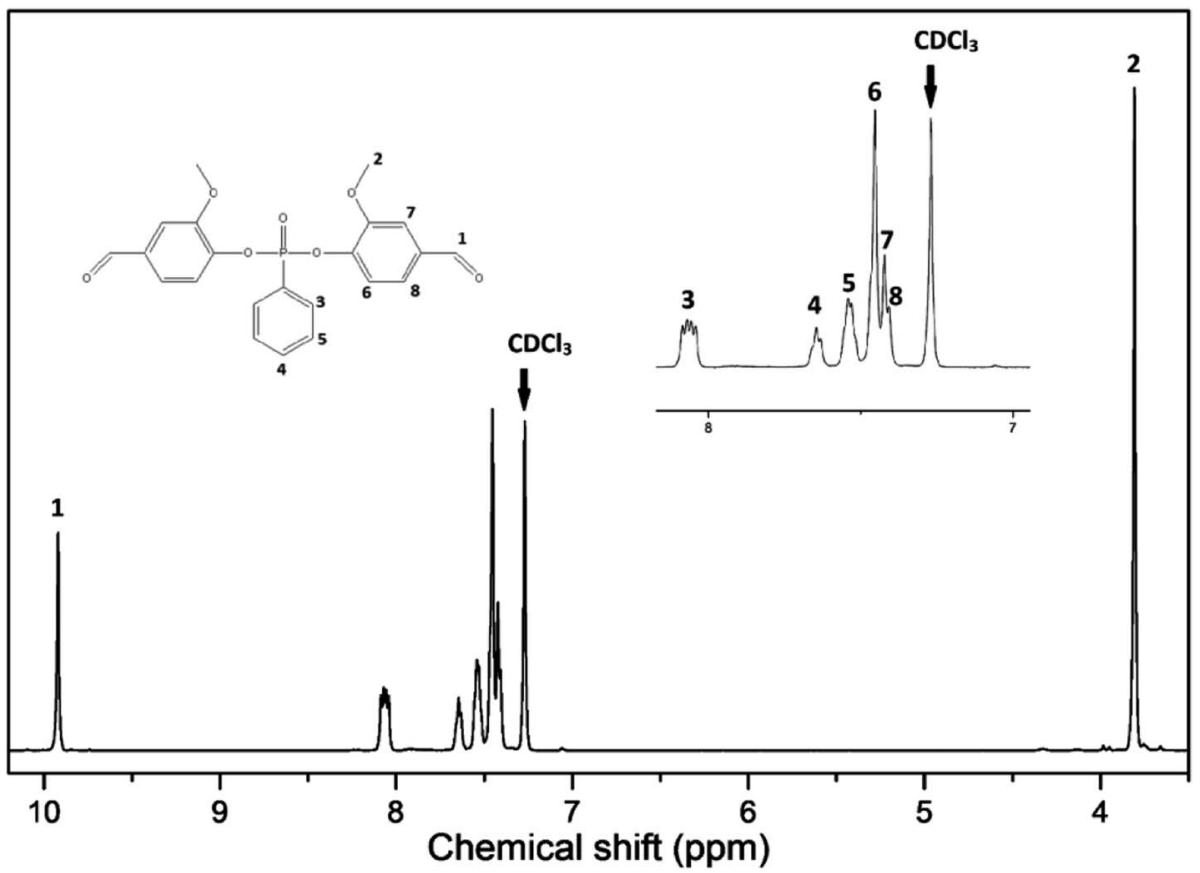

Fig. $3{ }^{1} \mathrm{H}-\mathrm{NMR}$ spectrum of VP.
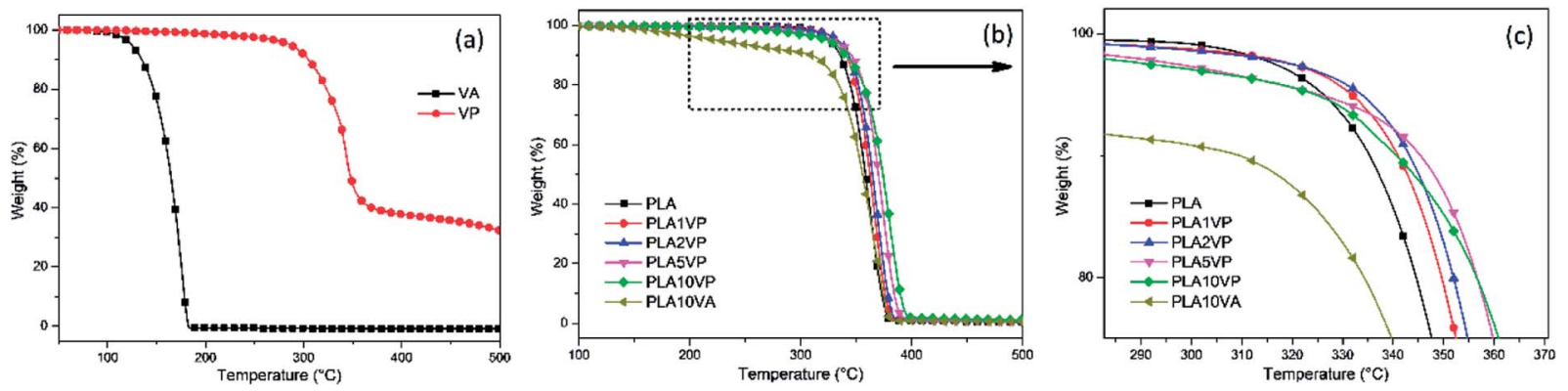

Fig. 4 TGA curves of (a) VP and VA; (b) $\&$ (c) PLA and PLA composites.

thermal stability led to the decomposition and evaporation of vanillin during the processing of its polymer composites. In comparison with pure vanillin, the thermal stability of the modified one, VP, was significantly improved, $T_{5 \%}$ and $T_{\max }$ were shifted from 124 and $175{ }^{\circ} \mathrm{C}$ to 286 and $343{ }^{\circ} \mathrm{C}$, respectively. It showed dramatic improvements of more than $160^{\circ} \mathrm{C}$. Furthermore, the residue of VP at $500{ }^{\circ} \mathrm{C}$ in a nitrogen atmosphere was around $30 \%$. These properties made VP a considerable additive for plastic.

The next step consisted in the evaluation of the effect of VP on the thermal oxidative decomposition of PLA. The relative thermal stabilities of the samples were compared by the value of $T_{5 \%}, T_{20 \%}, T_{\max }$ as well as char residue at $500{ }^{\circ} \mathrm{C}$. TG curves of the samples are presented in Fig. 4(b) and (c). The corresponding data are summarized in Table 1. As shown in Fig. 4(b), there was only one degradation step for the pure PLA ranging from 300 to $400{ }^{\circ} \mathrm{C}$. As for the PLA/VA composite, the degradation obviously consisted of two steps. The first step was from around 150 to $300^{\circ} \mathrm{C}$ and the weight loss in this stage was about
$10 \%$, which corresponded to the loading of vanillin in the composite. It can be also observed the slope of PLA/VA the temperature range 160 to $300{ }^{\circ} \mathrm{C}$ was almost constant, indicating the weight loss was only corresponding to the evaporation of vanillin. Comparing with the TG plots from Fig. 4(a), the onset temperature was higher than the initiation of the weight

Table 1 Data obtained from TGA plots of PLA and its composites ${ }^{a}$

\begin{tabular}{lllll}
\hline Sample & $T_{5 \%}\left({ }^{\circ} \mathrm{C}\right)$ & $T_{20 \%}\left({ }^{\circ} \mathrm{C}\right)$ & $T_{\max }\left({ }^{\circ} \mathrm{C}\right)$ & Residue $(\mathrm{wt} \%)$ \\
\hline PLA & 326 & 344 & 363 & 0 \\
PLA1VP & 331 & 350 & 366 & 0.8 \\
PLA2VP & 333 & 352 & 369 & 0.2 \\
PLA5VP & 325 & 357 & 373 & 0.3 \\
PLA10VP & 324 & 357 & 380 & 0.7 \\
PLA10VA & 225 & 334 & 362 & 0.6
\end{tabular}

${ }^{a} T_{x \%}$ was the temperature at $x \%$ weight loss of the samples. $T_{\max }$ was the temperature at the maximum rate of weight loss. Residue was the yield at $500{ }^{\circ} \mathrm{C}$. 
Table 2 LOI, UL94 and MFI results of PLA and PLA composites

\begin{tabular}{|c|c|c|c|c|}
\hline Samples & LOI (\%) & UL-94 rating $^{a}$ & MFI (g/10 min) & $\begin{array}{l}\text { Ignition of } \\
\text { cotton }\end{array}$ \\
\hline PLA & 21.4 & No rating & 9 & Yes \\
\hline PLA5VP & 25.8 & $\mathrm{~V}-0$ & 24 & No \\
\hline PLA10VP & 26.3 & $\mathrm{~V}-0$ & 55 & No \\
\hline PLA10VA & 19.5 & No rating & 22 & Yes \\
\hline
\end{tabular}

loss of VA. This should be due to that the PLA matrix was not melted until $160{ }^{\circ} \mathrm{C}$, and vanillin was completely released only when the sample was heated above its boiling temperature ( 285 $\left.{ }^{\circ} \mathrm{C}\right)$. Consequently, the thermal stability of PLA was decreased after the introduction of VA.

In the case of PLA/VP composites, based on the results in Table 1 , the residue at $500{ }^{\circ} \mathrm{C}$ remained at the same level, the differences were negligible. In the meantime, the value of $T_{20 \%}$ of PLA1VP, PLA2VP, PLA5VP and PLA10VP were shifted from $344^{\circ} \mathrm{C}$ of PLA to $350,352,357$ and $357^{\circ} \mathrm{C}$, respectively, while $T_{\text {max }}$ shifted from $363{ }^{\circ} \mathrm{C}$ of PLA to $366,369,373$ and $380{ }^{\circ} \mathrm{C}$, respectively, indicating the thermal stability of polymer matrix was improved, even when the loading of VP was only $1 \%$. The improvement was stronger as the loading of VP rose. However, another interesting result found in TG was that the value of $T_{5 \%}$ of the samples reached the maximum when the loading of VP was $2 \%$. It can be supposed that on one hand, the introduction of VP improved the thermal stability of PLA; on the other hand, VP decomposed at a lower temperature than PLA. The decomposition of VP was not noticeable when the loading was lower than $2 \%$. However, as the samples were further heated, the interaction between VP and PLA occurred. Hence, $T_{20 \%}$ and $T_{\max }$ shifted to a higher temperature as the loading of VP increased.

\section{Fire behaviors}

LOI and UL-94. In this work, LOI and UL-94 were applied to evaluate the flammability of PLA composites. LOI is a quantitative method which shows the minimum oxygen concentration of an oxygen/nitrogen mixture to maintain the combustion of the sample, while the UL-94 measurements provide a qualitative classification. ${ }^{44}$ The results of the LOI, UL-94 and MFI tests of PLA and PLA composites are summarized in Table 2. Results showed that the LOI value of pure PLA was $21.4 \%$, revealing that PLA was an easily flammable material. It was also observed that during the UL-94 tests, the samples were burned to the sample holder with intensive burning dripping behavior, as the cotton was ignited by the droplets. With $10 \mathrm{wt} \%$ of VA, some of the samples showed self-extinguishment in 10 seconds. However, the cotton under the samples was still ignited by the flaming dripping, and the LOI value decreased from $21.4 \%$ of PLA to $19.5 \%$. Reason for this result was that vanillin was flammable and volatile at high temperature, it was ignited more easily than PLA. By contrast, after the introduction of VP, the samples showed a positive effect both in LOI and UL-94 tests. When the loading of VP was $5 \mathrm{wt} \%$ and $10 \mathrm{wt} \%$, the LOI values of the composites were improved to $25.8 \%$ and $26.3 \%$. Furthermore, both of the composites passed V-0 level in UL-94 tests, and the cotton was not ignited. It was due to the fact that the introduction of VA and VP had changed the melt flow behavior of PLA, evidenced by the significant elevation of MFI (Table 2). The ease of flow took heat away in large scale, ${ }^{45}$ leading to better UL94 results. Nevertheless, all the results suggested that VP provided good flame retardancy to PLA.

Cone calorimeter test (CCT). Cone calorimeter test (CCT) is one of the most efficient methods to predict the flame retardant properties of polymeric materials. Curves obtained from the CCT are presented in Fig. 5 and 6, the corresponding characteristic parameters are collected in Table 3 , including time to

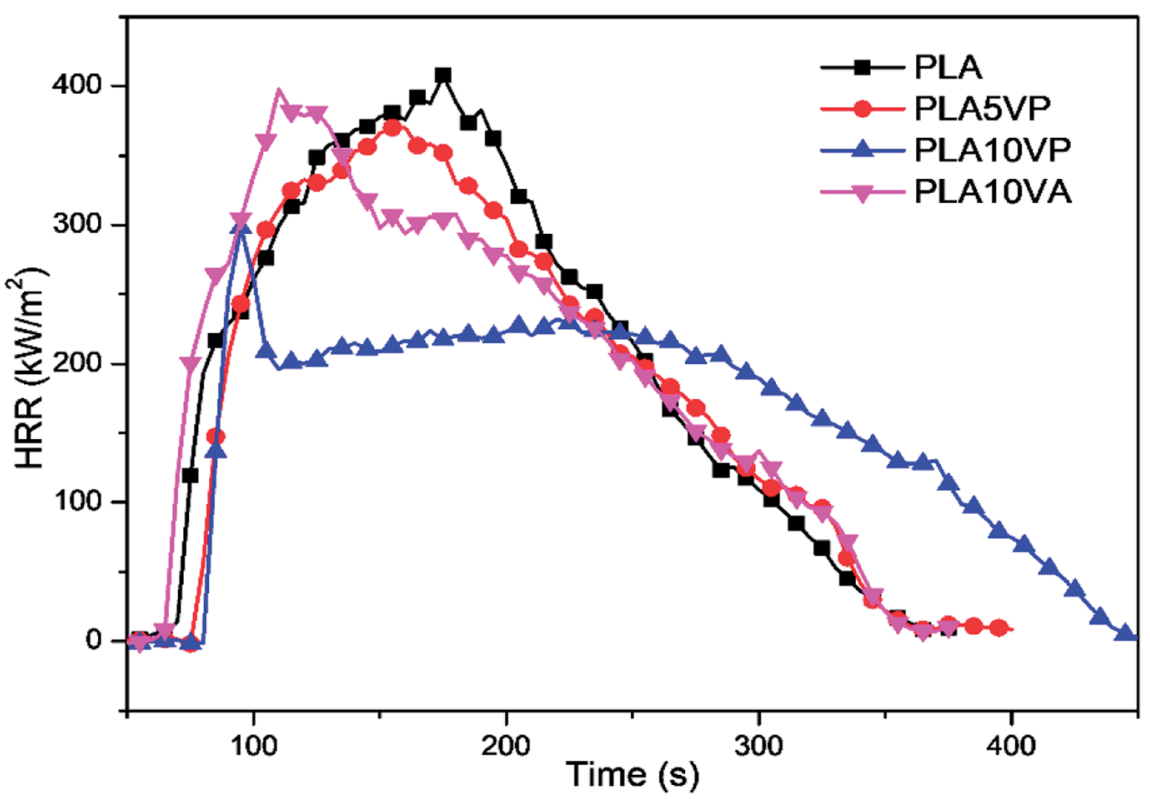

Fig. 5 HRR plots of PLA and PLA composites. 

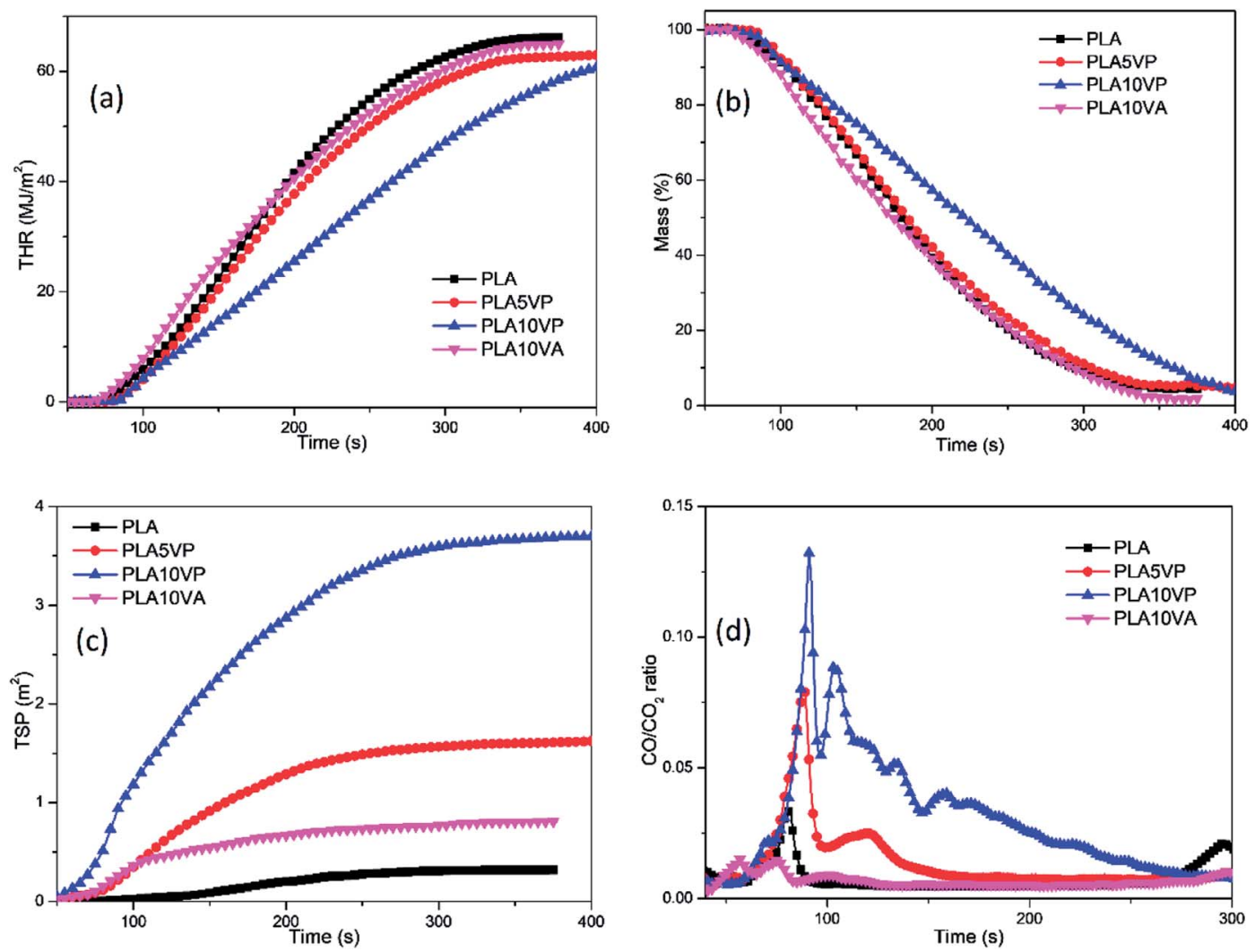

Fig. 6 THR (a), Mass loss (b), TSP (c) and $\mathrm{CO} / \mathrm{CO}_{2}$ ratio (d) plots of PLA and PLA composites.

ignition (TTI), peak of heat release rate (pHRR), total heat release (THR) and residual mass. ${ }^{46}$

Based on the results obtained from CCT, it was observed that TTI of PLA was $68 \mathrm{~s}$. When neat PLA was ignited, it exhibited fiercely combustion and consumed all the material, showing a total heat of $66.0 \pm 0.9 \mathrm{MJ} \mathrm{m}^{-2}$, with a pHRR value of $407 \pm 16$ $\mathrm{kW} \mathrm{m}^{-2}$. After the introduction of pure vanillin, the pHRR and THR value of PLA10VA decreased slightly to $396 \pm 2 \mathrm{~kW} \mathrm{~m}^{-2}$ and $64.9 \pm 0.7 \mathrm{MJ} \mathrm{m}^{-2}$, respectively. However, the TTI was $64 \mathrm{~s}$, which was $4 \mathrm{~s}$ earlier than pure PLA. It could be explained by the volatile nature of vanillin. When the material was melted by heat radiation, vanillin was evaporated and then decomposed earlier than PLA into gaseous flammable products. Hence, the specimen was ignited faster than neat PLA. In comparison, VP and PLA demonstrated better cooperation towards flame retardancy. The pHRR and THR values of PLA5VP were reduced to $370 \pm 14 \mathrm{~kW} \mathrm{~m}^{-2}$ and $62.8 \pm 1.7 \mathrm{MJ} \mathrm{m}^{-2}$, respectively. When the loading of VP increased to $10 \mathrm{wt} \%$, the pHRR of sample decreased further to $292 \pm 28 \mathrm{~kW} \mathrm{~m}^{-2}$ and THR value accounted at $62.6 \pm 1.7 \mathrm{MJ} \mathrm{m}^{-2}$. In addition, TTI values of PLA/VP composites were delayed to 76 and $79 \mathrm{~s}$ respectively, showing notable resistance against ignition.

As shown in Fig. 5, the HRR curves of pure PLA, PLA5VP and PLA10VA exhibited a similar pattern. After the ignition, the heat release increased fast and continuously to the peak, suggesting that the flame spread rapidly into the surface of the entire specimen. The broad peak indicated that the combustion consumed all the material without any inhibition, corresponding to the slow decreasing of HRR after the peaks. Interestingly, the HRR of PLA10VP grew rapidly to the peak after the ignition and decreased immediately from $292 \mathrm{~kW} \mathrm{~m}^{-2}$ to around $200 \mathrm{~kW} \mathrm{~m}{ }^{-2}$. The reason of that was due to the decomposition of VP, which simultaneously provide combustible gas products and phosphorus containing segments. The combustible products were ignited and contributed to the strong release of heat. And immediately the combustion was suppressed by the phosphorus containing segments due to the radical capture effect. As a consequence, the HRR of PLA10VP exhibited a sharp peak direct after the ignition due to the evolved phosphor containing radical scavenger. When all these products were consumed, the combustion behavior of the rest specimen was similar like pure PLA, showing broad peak until all the material was burned off. Hence, it can be concluded that the incorporation of VP can significantly reduce and delay the heat release in PLA composites.

As mentioned before, although the introduction of both VA and VP can reduce the THR of specimens in comparison with pure PLA, the reduction was not that distinct. However, in

Table 3 Data obtained from CCT of PLA and PLA composites

\begin{tabular}{lllll} 
Samples & TTI $(\mathrm{s})$ & pHRR $\left(\mathrm{kW} \mathrm{m}^{-2}\right)$ & THR $\left(\mathrm{MJ} \mathrm{m}^{-2}\right)$ & Residue $(w t \%)$ \\
\hline PLA & $68 \pm 3$ & $407 \pm 16$ & $66.0 \pm 0.9$ & $0.5 \pm 0.2$ \\
PLA5VP & $76 \pm 4$ & $370 \pm 14$ & $62.8 \pm 1.1$ & $6.0 \pm 0.1$ \\
PLA10VP & $79 \pm 2$ & $292 \pm 28$ & $62.6 \pm 1.7$ & $7.7 \pm 0.5$ \\
PLA10VA & $64 \pm 5$ & $396 \pm 2$ & $64.9 \pm 0.7$ & $0.9 \pm 0.3$
\end{tabular}


Fig. 6(a) more obvious difference of the development of THR could be found: the curve of PLA10VP was almost linear and its slope was much lower than that of other curves, indicating that the combustion of PLA10VP was much slower. Hence, its THR at the same time after the beginning of measurement was also much lower than that of other samples. This result also matched with the curves of mass loss of the samples based on Fig. 6(b). The mass loss rate of PLA10VP kept almost constant and was much slower than that of other samples.

\section{PLA}
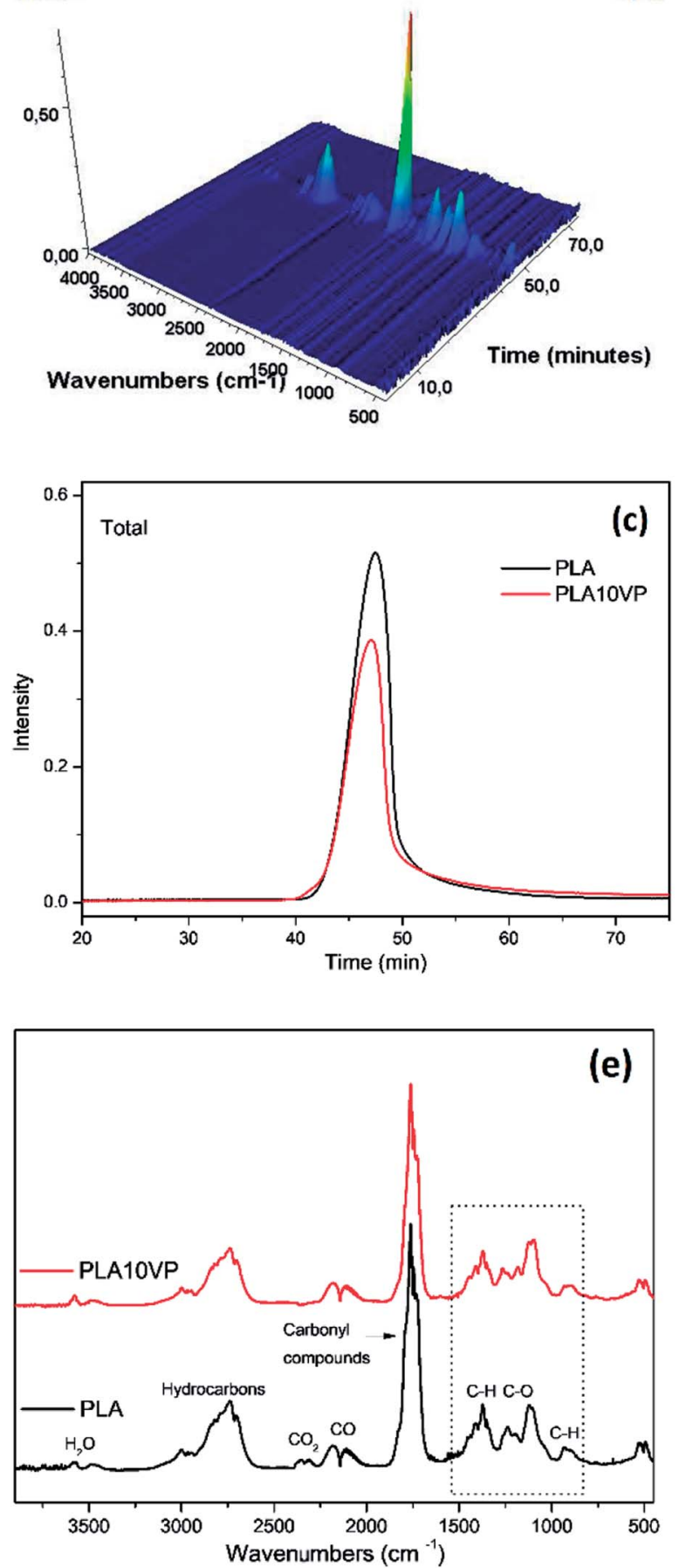

(a)
Considering the few residues remaining after the CCT (Table 3 ), it was unlikely that those residues could act as a barrier or protective layer to reduce the heat release. So the action in gaseous phase should mainly contribute to the flame retardant property of the PLA composites. The release of gaseous products and smoke were very important parameters to estimate the combustion behavior of materials. The total smoke production (TSP) and the ratio of $\mathrm{CO} / \mathrm{CO}_{2}$ are presented in Fig. 6(c) and (d). It can be seen from Fig. 6(d), the intensity of the first peak of
PLA10VP
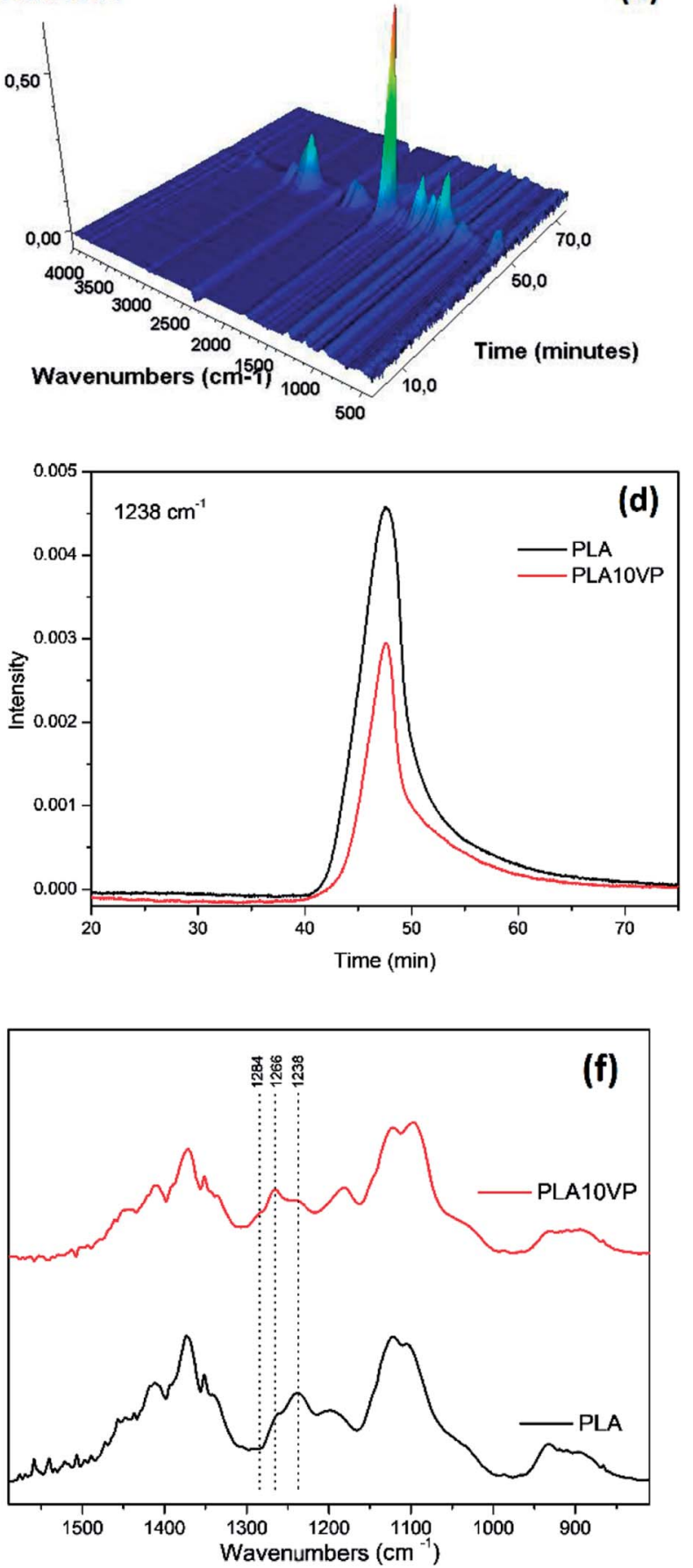

Fig. 7 3D-images of evolved gaseous products for (a) PLA (b) PLA10VP; (c) total absorbance vs. time for PLA and PLA10VP; (d) absorbance at $1238 \mathrm{~cm}^{-1}$ vs. time for PLA and PLA10VP (e) at $T_{\max }$ for PLA and PLA10VP; (f) zoom in on selected area. ( $T_{\text {max }}$ appeared at 47 min). 
pure PLA was around 0.03, while that of PLA5VP and PLA10VP was around 0.08 and 0.13 respectively. It was considered to be associated with the radical scavenger effect of phosphorus containing products evolved by VP, which led to incomplete combustion of the samples. The double peaks at the beginning of the curve of PLA10VA could be explained by the earlier ignition of the volatile vanillin and its acceleration effect on the ignition of PLA.

Analysis of evolved gaseous products. To further understand the decomposition and flame retardant mechanism, TGA-FTIR was employed to study the evolved gaseous products. The 3-D images and FTIR spectra of involved products for PLA and PLA10VP are shown in Fig. 7. The thermal degradation process of PLA has been intensively studied by many researchers. ${ }^{47-49}$ According to the results, the main gas products from degradation products of PLA were water $\left(3577 \mathrm{~cm}^{-1}\right)$, hydrocarbons (2900-3000 $\left.\mathrm{cm}^{-1}\right), \mathrm{CO}_{2}\left(2350 \mathrm{~cm}^{-1}\right), \mathrm{CO}\left(2114\right.$ and $\left.2182 \mathrm{~cm}^{-1}\right)$, carbonyl compounds $\left(1762 \mathrm{~cm}^{-1}\right)$ and aliphatic ethers $(1100-$ $1250 \mathrm{~cm}^{-1}$ ). An obvious decreasing at $1238 \mathrm{~cm}^{-1}$ (related to $\mathrm{C}-\mathrm{O}$ stretching) for PLA10VP was observed.
In addition, the total absorbance of PLA was also stronger than that of PLA10VP, indicating that the incorporation of VP led to an overall reduction of evolved gaseous products. Furthermore, as can be seen in Fig. 7(e), two bands at 1266 and $1284 \mathrm{~cm}^{-1}$ appeared, which could be assigned to $\mathrm{P}-\mathrm{C}$ and $\mathrm{P}=\mathrm{O}$, respectively. This could be the reason for the reduction of $\mathrm{C}-\mathrm{O}$ containing products evolved. The phosphorus containing compounds was considered to be able to accelerate the radical reactions especially at high temperature. ${ }^{49}$

\section{Rheological properties}

The rheological performance of PLA and PLA composites are presented in Fig. 8. The complex viscosity of neat PLA presented low dependency in lower frequency range. A Newtonian plateau was obtained in the range 0.1-10 $\mathrm{rad} \mathrm{s}^{-1}$, while a slight shear thinning behavior was observed at higher shear rate. The complex viscosity gradually decreased with rising VP loading, indicating that VP possessed remarkable plasticization effect for PLA. For PLA10VP, the complex viscosity was reduced by more than an order of magnitude. In addition, the Newtonian
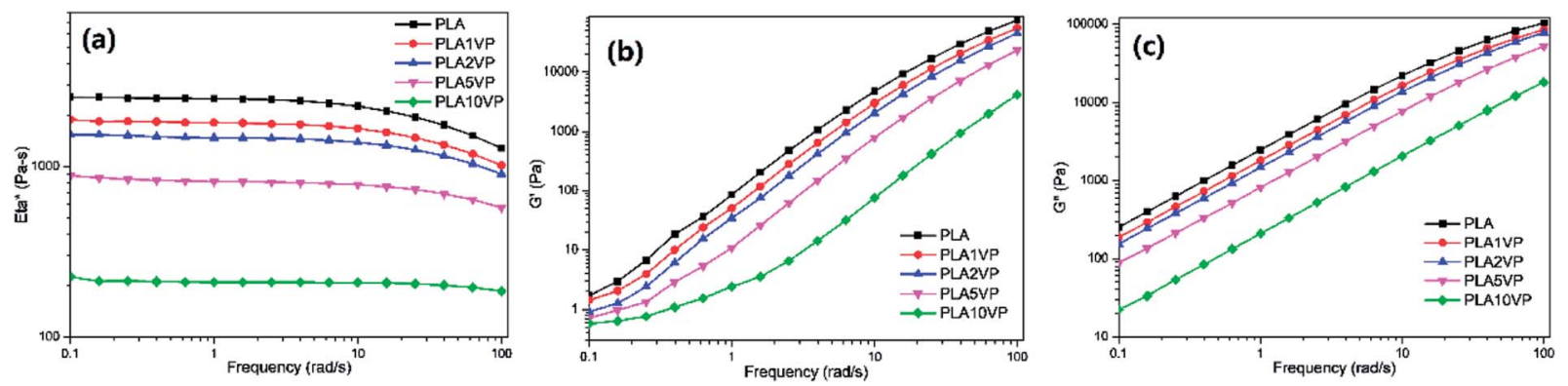

Fig. 8 Rheological properties of PLA and PLA composites: (a) complex viscosity; (b) storage modulus; (c) loss modulus.

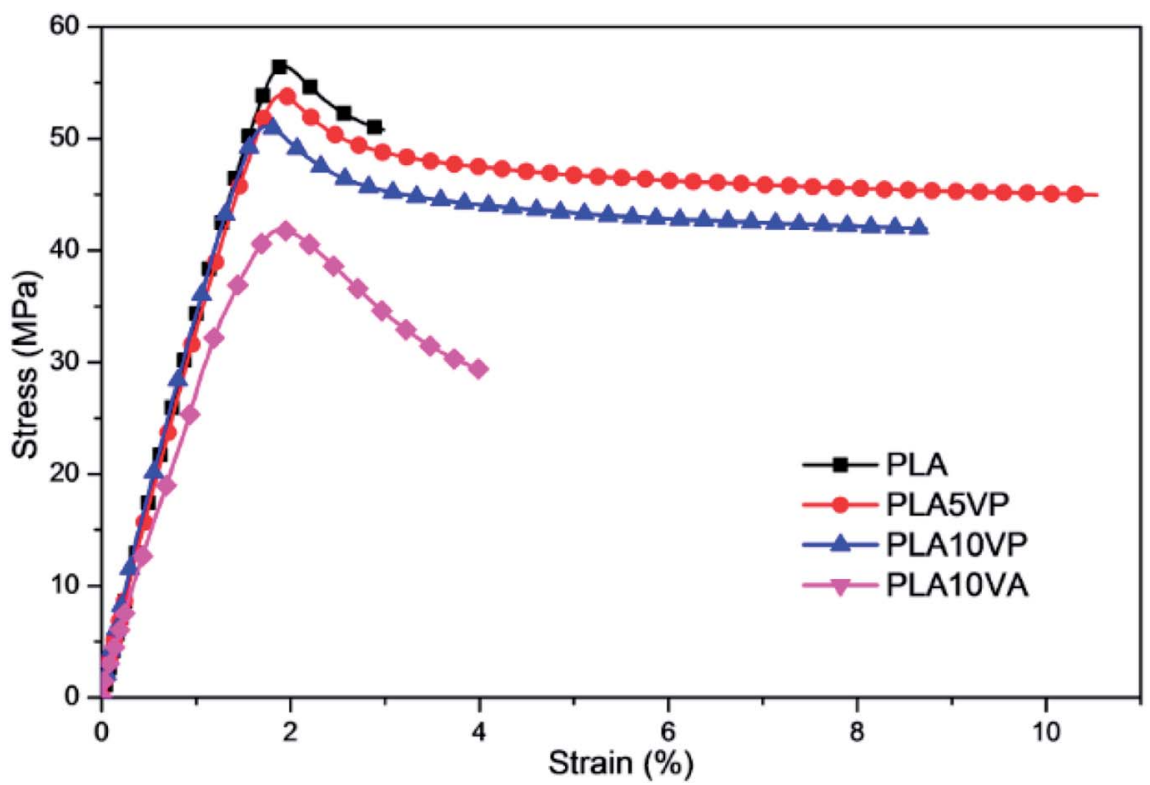

Fig. 9 Tensile test curves of PLA and PLA composites. 
Table 4 Data obtained from tensile test of PLA and PLA composites

\begin{tabular}{lllrr}
\hline Sample & $\begin{array}{l}\text { Young's } \\
\text { modulus (MPa) }\end{array}$ & $\begin{array}{l}\text { Tensile strength } \\
(\mathrm{MPa})\end{array}$ & \multicolumn{1}{c}{$\begin{array}{l}\text { Elongation at } \\
\text { break }(\%)\end{array}$} & $\begin{array}{l}\text { Impact strength } \\
\left.(\mathrm{kJ} \mathrm{m})^{-2}\right)\end{array}$ \\
\hline PLA & $3700 \pm 100$ & $57 \pm 1$ & $3 \pm 1$ & $16 \pm 2$ \\
PLA5VP & $3500 \pm 100$ & $54 \pm 1$ & $11 \pm 3$ & $18 \pm 3$ \\
PLA10VP & $3500 \pm 200$ & $52 \pm 1$ & $9 \pm 3$ & $19 \pm 2$ \\
PLA10VA & $2900 \pm 100$ & $42 \pm 1$ & $4 \pm 2$ & $17 \pm 3$
\end{tabular}

plateau was extended to high frequency range, almost no shear thinning behavior was observed. For all the samples, $G^{\prime \prime}$ was overall higher than $G^{\prime}$, indicating that the samples were more viscous than elastic. Comparing with neat PLA, both $G^{\prime}$ and $G^{\prime \prime}$ of composites were declined with increasing VP loading. In case of PLA10VP, $G^{\prime \prime}$ decreased by two over the entire frequency range, while such notable difference in $G^{\prime}$ only observed at higher shear rate. In summary, the lubricant effect of VP led to the decrement of strength provided by the entanglements of PLA chain, thereby reducing the melt viscosity and enhancing the processability of PLA. Since the dripping behavior could be considered as a low shear rate phenomenon, the results of rheological measurements further supported the results obtain in LOI and UL-94 tests.

\section{Mechanical properties}

When developing a new functional additive for polymeric materials (in this work, flame retardant), it is also necessary to evaluate the impact of incorporating this additive to other properties of the final composites. The stress-strain curves of PLA and PLA composites are shown in Fig. 9, and the results of Young's modulus, tensile strength and elongation at break are summarized in Table 4.

It is widely known that PLA is a stiff thermoplastic polymer. Based on the results, pure PLA exhibited a high rigidity $(3700 \pm$ $100 \mathrm{MPa})$, a high tensile strength $(57 \pm 1 \mathrm{MPa})$ and a low elongation at break $(3 \pm 1 \%)$. Despite the introduction of VA improved slightly the elongation at break to $4 \pm 2 \%$, some mechanical properties were notably deteriorated: the Young's modulus decreased to $2900 \pm 100 \mathrm{MPa}$ while the tensile strength declined to $42 \pm 1 \mathrm{MPa}$. In case of PLA/VP composites, comparing the significant improvement of elongation at break of PLA/VP composites ( $11 \pm 3 \%$ for PLA5VP), the decreasing of tensile strength and Young's modulus was negligible. In contrast, the introduction of some molecular additives led to increase of the impact resistance of PLA. The impact strength of PLA10VA, PLA5VP and PLA10VP was improved from $16 \pm 2 \mathrm{~kJ}$ $\mathrm{m}^{-2}$ of PLA to $17 \pm 3,18 \pm 3$ and $19 \pm 2 \mathrm{~kJ} \mathrm{~m}^{-2}$, respectively. This result can be explained by the lubricant effect of the filler, which enhanced the chain mobility of PLA.

As the SEM results of the samples showed (S3 $\dagger$ ), the particle size of VA was much bigger than that of VP due to the intermolecular hydrogen bonding. So the plasticization effect of VP to PLA was better than that of VA. In the meantime, the agglomeration caused stress concentration in composites. It can be seen from the specimens after tensile tests that the microcracks of
PLA/VA specimens were more random and developed from the edge to the middle of specimens, and most of the cracks crossed less than $1 / 4$ of the specimen's width (shown in S4 $\uparrow$ ). By contrast, the microcracks of PLA/VP specimens were finer and most of them crossed the specimen's width. The cracks developed from the breakage to both ends of the specimens. This phenomenon indicated that the stress transfer across specimens was much better in PLA/VP composites due to the homogeneous structure. This was in good agreement with the better dispersion of VP observed in SEM. Consequently, fillers had a plasticization effect, which caused decreasing of stiffness and improvement of elongation at break. In the meantime, the agglomeration of filler could also cause deterioration of various mechanical properties. Hence, as the loading of VP rose, there was more chance that agglomeration formed, so the elongation at break of samples decreased. Nevertheless, VP could significantly improve the elongation of PLA with similar tensile strength.

\section{Conclusion}

In this work, a novel bio-based flame retardant for PLA was successfully synthesized from vanillin and characterized via NMR and FTIR. With only $5 \mathrm{wt} \%$ loading of VP, PLA passed UL-94 V0 classification and the LOI value increased from $21.4 \%$ to $25.8 \%$. As the loading increased to $10 \mathrm{wt} \%$, LOI value was further improved to $26.3 \%$. An obvious quenching effect was observed in the cone calorimeter test. The PHRR value was suppressed from $407 \mathrm{~kW} \mathrm{~m}^{-2}$ for neat PLA to $292 \mathrm{~kW} \mathrm{~m}^{-2}$. Besides, low char residue and significant increase of $\mathrm{CO}$ release indicated that gas phase action was the main flame retardant mechanism. $\mathrm{PO}{ }^{*}$ evolved from thermal decomposition of VP was considered to be responsible for the improvement of flame retardancy. Furthermore, the thermal stability of PLA was improved as the loading of VP increased. The reason was considered to be the antioxidant effect of vanillin segment. Additionally, PLA/VP composites exhibited remarkable improvement in elongation at break. With $5 \mathrm{wt} \%$ loading of VP, the elongation at break of PLA was enhanced from $3 \%$ to $11 \%$.

\section{Conflicts of interest}

There are no conflicts to declare.

\section{Acknowledgements}

The authors would thank the financial support from the China Scholarship Council (201308080080) and Leibniz Institute for Polymer Research Dresden. 


\section{References}

1 R. P. Babu, K. O'Connor and R. Seeram, Current progress on bio-based polymers and their future trends, Prog. Biomater., 2013, 2(1), 8.

2 J. Ren, Biodegradable Poly(Lactic Acid): Synthesis, Modification, Processing. Springer, 2010.

3 M. P. Arrieta, M. D. M. Castro-López, E. Rayón, L. F. BarralLosada, J. M. López-Vilariño, J. López and M. V. GonzálezRodríguez, Plasticized Poly(lactic acid)Poly(hydroxybutyrate) (PLA-PHB) Blends Incorporated with Catechin Intended for Active Food-Packaging Applications, J. Agric. Food Chem., 2014, 62(41), 10170-10180.

4 E. Castro-Aguirre, F. Iñiguez-Franco, H. Samsudin, X. Fang and R. Auras, Poly(lactic acid)-Mass production, processing, industrial applications, and end of life, Adv. Drug Delivery Rev., 2016, 107(suppl. C), 333-366.

5 Y. Chen, L. M. Geever, J. A. Killion, J. G. Lyons, C. L. Higginbotham and D. M. Devine, Review of Multifarious Applications of Poly (Lactic Acid), Polym.-Plast. Technol. Eng., 2016, 55(10), 1057-1075.

6 K. Fukushima and Y. Kimura, Stereocomplexed polylactides (Neo-PLA) as high-performance bio-based polymers: their formation, properties, and application, Polym. Int., 2006, 55(6), 626-642.

7 M. Jamshidian, E. A. Tehrany, M. Imran, M. Jacquot and S. Desobry, Poly-Lactic Acid: production, applications, nanocomposites, and release studies, Compr. Rev. Food Sci. Food Saf., 2010, 9(5), 552-571.

8 E. T. Vink, K. R. Rabago, D. A. Glassner and P. R. Gruber, Applications of life cycle assessment to NatureWorks ${ }^{\mathrm{TM}}$ polylactide (PLA) production, Polym. Degrad. Stab., 2003, 80(3), 403-419.

9 V. K. K. V. Y. Horikoshi, Bio-based polymers, Fujitsu Sci. Tech. J., 2005, 41(2), 173-180.

$10 \mathrm{~S}$. Bourbigot and G. Fontaine, Flame retardancy of polylactide: an overview, Polym. Chem., 2010, 1(9), 14131422.

11 M. Pluta, A. Galeski, M. Alexandre, M. A. Paul and P. Dubois, Polylactide/montmorillonite nanocomposites and microcomposites prepared by melt blending: Structure and some physical properties, J. Appl. Polym. Sci., 2002, 86(6), 1497-1506.

12 Y.-C. Li, J. Schulz, S. Mannen, C. Delhom, B. Condon, S. Chang, M. Zammarano and J. C. Grunlan, Flame Retardant Behavior of Polyelectrolyte-Clay Thin Film Assemblies on Cotton Fabric, ACS Nano, 2010, 4(6), 33253337.

13 G. Laufer, C. Kirkland, A. A. Cain and J. C. Grunlan, ClayChitosan Nanobrick Walls: Completely Renewable Gas Barrier and Flame-Retardant Nanocoatings, ACS Appl. Mater. Interfaces, 2012, 4(3), 1643-1649.

14 X. Wang, Y. Sporer, A. Leuteritz, I. Kuehnert, U. Wagenknecht, G. Heinrich and D.-Y. Wang, Comparative study of the synergistic effect of binary and ternary $\mathrm{LDH}$ with intumescent flame retardant on the properties of polypropylene composites, RSC Adv., 2015, 5(96), 78979-78985.

15 Y. Gao, Q. Wang, J. Wang, L. Huang, X. Yan, X. Zhang, Q. He, Z. Xing and Z. Guo, Synthesis of Highly Efficient Flame Retardant High-Density Polyethylene Nanocomposites with Inorgano-Layered Double Hydroxides As Nanofiller Using Solvent Mixing Method, ACS Appl. Mater. Interfaces, 2014, 6(7), 5094-5104.

16 N.-J. Kang, D.-Y. Wang, B. Kutlu, P.-C. Zhao, A. Leuteritz, U. Wagenknecht and G. Heinrich, A New Approach to Reducing the Flammability of Layered Double Hydroxide (LDH)-Based Polymer Composites: Preparation and Characterization of Dye Structure-Intercalated LDH and Its Effect on the Flammability of Polypropylene-Grafted Maleic Anhydride/d-LDH Composites, ACS Appl. Mater. Interfaces, 2013, 5(18), 8991-8997.

17 S. Naseem, S. P. Lonkar, A. Leuteritz and F. J. W. J. Labuschagné, Different transition metal combinations of $\mathrm{LDH}$ systems and their organic modifications as UV protecting materials for polypropylene (PP), RSC Adv., 2018, 8(52), 29789-29796.

18 X. Wang, L. Song, H. Yang, H. Lu and Y. Hu, Synergistic Effect of Graphene on Antidripping and Fire Resistance of Intumescent Flame Retardant Poly(butylene succinate) Composites, Ind. Eng. Chem. Res., 2011, 50(9), 5376-5383.

19 X. Mu, B. Yuan, W. Hu, S. Qiu, L. Song and Y. Hu, Flame retardant and anti-dripping properties of polylactic acid/ poly(bis(phenoxy)phosphazene)/expandable graphite composite and its flame retardant mechanism, RSC Adv., 2015, 5(93), 76068-76078.

20 X. Wang, E. N. Kalali and D.-Y. Wang, An in situ polymerization approach for functionalized MoS2/nylon-6 nanocomposites with enhanced mechanical properties and thermal stability, J. Mater. Chem. A, 2015, 3(47), 2411224120.

21 G. Fontaine and S. Bourbigot, Intumescent polylactide: A nonflammable material, J. Appl. Polym. Sci., 2009, 113(6), 3860-3865.

22 T. D. Hapuarachchi and T. Peijs, Multiwalled carbon nanotubes and sepiolite nanoclays as flame retardants for polylactide and its natural fibre reinforced composites, Composites, Part A, 2010, 41(8), 954-963.

23 G. Fontaine, A. Gallos and S. Bourbigot, Role of montmorillonite for enhancing fire retardancy of intumescent PLA, Fire Saf. Sci., 2014, 11, 808-820.

24 S. Li, H. Yuan, T. Yu, W. Yuan and J. Ren, Flame-retardancy and anti-dripping effects of intumescent flame retardant incorporating montmorillonite on poly (lactic acid), Polym. Adv. Technol., 2009, 20(12), 1114-1120.

25 D.-F. Li, X. Zhao, Y.-W. Jia, X.-L. Wang and Y.-Z. Wang, Tough and flame-retardant poly(lactic acid) composites prepared via reactive blending with biobased ammonium phytate and in situ formed crosslinked polyurethane, Compos. Comm., 2018, 8, 52-57.

26 Y. P. Song, D. Y. Wang, X. L. Wang, L. Lin and Y. Z. Wang, A method for simultaneously improving the flame retardancy 
and toughness of PLA, Polym. Adv. Technol., 2011, 22(12), 2295-2301.

27 Y. Sun, S. Sun, L. Chen, L. Liu, P. Song, W. Li, Y. Yu, L. Fengzhu, J. Qian and H. Wang, Flame retardant and mechanically tough poly(lactic acid) biocomposites via combining ammonia polyphosphate and polyethylene glycol, Compos. Comm., 2017, 6, 1-5.

28 K. Bocz, B. Szolnoki, A. Marosi, T. Tábi, M. WladykaPrzybylak and G. Marosi, Flax fibre reinforced PLA/TPS biocomposites flame retarded with multifunctional additive system, Polym. Degrad. Stab., 2014, 106(suppl. C), 63-73.

29 X. Wang, Y. Hu, L. Song, S. Xuan, W. Xing, Z. Bai and H. Lu, Flame Retardancy and Thermal Degradation of Intumescent Flame Retardant Poly(lactic acid)/Starch Biocomposites, Ind. Eng. Chem. Res., 2011, 50(2), 713-720.

$30 \mathrm{~S}$. He, The Mechanism and Application of RDP Cellulose as Flame Retardant Agent and Mechanical Reinforcement into PLA-based Biodegradable Nanocomposites, State University of New York at Stony Brook, 2016.

31 J. X. Feng, S. P. Su and J. Zhu, An intumescent flame retardant system using $\beta$-cyclodextrin as a carbon source in polylactic acid (PLA), Polym. Adv. Technol., 2011, 22(7), 1115-1122.

32 R. Zhang, X. Xiao, Q. Tai, H. Huang and Y. Hu, Modification of lignin and its application as char agent in intumescent flame-retardant poly (lactic acid), Polym. Eng. Sci., 2012, 52(12), 2620-2626.

33 V. K. Thakur, M. K. Thakur, P. Raghavan and M. R. Kessler, Progress in Green Polymer Composites from Lignin for Multifunctional Applications: A Review, ACS Sustainable Chem. Eng., 2014, 2(5), 1072-1092.

34 L. Costes, F. Laoutid, S. Brohez, C. Delvosalle and P. Dubois, Phytic acid-lignin combination: A simple and efficient route for enhancing thermal and flame retardant properties of polylactide, Eur. Polym. J., 2017, 94(suppl. C), 270-285.

35 X. Wang, E. N. Kalali and D.-Y. Wang, Renewable CardanolBased Surfactant Modified Layered Double Hydroxide as a Flame Retardant for Epoxy Resin, ACS Sustainable Chem. Eng., 2015, 3(12), 3281-3290.

36 X.-W. Cheng, J.-P. Guan, R.-C. Tang and K.-Q. Liu, Phytic acid as a bio-based phosphorus flame retardant for poly(lactic acid) nonwoven fabric, J. Cleaner Prod., 2016, 124(suppl. C), 114-119.

37 A. Celebioglu, F. Kayaci-Senirmak, S. Ipek, E. Durgun and T. Uyar, Polymer-free nanofibers from vanillin/cyclodextrin inclusion complexes: high thermal stability, enhanced solubility and antioxidant property, Food Funct., 2016, 7(7), 3141-3153.
38 L. F. Dalmolin, N. M. Khalil and R. M. Mainardes, Delivery of vanillin by poly (lactic-acid) nanoparticles: development, characterization and in vitro evaluation of antioxidant activity, Mater. Sci. Eng. C., 2016, 62, 1-8.

39 M. Fache, B. Boutevin and S. Caillol, Vanillin production from lignin and its use as a renewable chemical, ACS Sustainable Chem. Eng., 2015, 4(1), 35-46.

40 M. Fache, E. Darroman, V. Besse, R. Auvergne, S. Caillol and B. Boutevin, Vanillin, a promising biobased building-block for monomer synthesis, Green Chem., 2014, 16(4), 19871998.

41 S. Gunasekaran and S. Ponnusamy, Vibrational spectra and normal coordinate analysis on an organic non-linear optical crystal-3-methoxy-4-hydroxy benzaldehyde, 2005.

42 Y. Liu, Y.-T. Pan, X. Wang, P. Acuña, P. Zhu, U. Wagenknecht, G. Heinrich, X.-Q. Zhang, R. Wang and D.-Y. Wang, Effect of phosphorus-containing inorganicorganic hybrid coating on the flammability of cotton fabrics: Synthesis, characterization and flammability, Chem. Eng. J., 2016, 294(suppl. C), 167-175.

43 H.-J. Lin, S.-R. Liu, L.-J. Han, X.-M. Wang, Y.-J. Bian and L.-S. Dong, Effect of a phosphorus-containing oligomer on flame-retardant, rheological and mechanical properties of poly (lactic acid), Polym. Degrad. Stab., 2013, 98(7), 13891396.

44 F. Laoutid, L. Bonnaud, M. Alexandre, J. M. Lopez-Cuesta and P. Dubois, New prospects in flame retardant polymer materials: From fundamentals to nanocomposites, Mater. Sci. Eng., R, 2009, 63(3), 100-125.

45 Z. Li, P. Wei, Y. Yang, Y. Yan and D. Shi, Synthesis of a hyperbranched poly(phosphamide ester) oligomer and its high-effective flame retardancy and accelerated nucleation effect in polylactide composites, Polym. Degrad. Stab., 2014, 110, 104-112.

46 G. Gallina, E. Bravin, C. Badalucco, G. Audisio, M. Armanini, A. De Chirico and F. Provasoli, Application of cone calorimeter for the assessment of class of flame retardants for polypropylene, Fire Mater., 1998, 22(1), 15-18.

$47 \mathrm{X}$. Chen, J. Zhuo and C. Jiao, Thermal degradation characteristics of flame retardant polylactide using TG-IR, Polym. Degrad. Stab., 2012, 97(11), 2143-2147.

48 H. Zou, C. Yi, L. Wang, H. Liu and W. Xu, Thermal degradation of poly (lactic acid) measured by thermogravimetry coupled to Fourier transform infrared spectroscopy, J. Therm. Anal. Calorim., 2009, 97(3), 929.

49 X. Zhao, F. R. Guerrero, J. Llorca and D.-Y. Wang, New Superefficiency Flame-Retardant Bioplastic Poly(lactic acid): Flammability, Thermal Decomposition Behavior, and Tensile Properties, ACS Sustainable Chem. Eng., 2016, 4(1), 202-209. 